\title{
1p/19q Deletion Analysis Testing Method
}

National Cancer Institute

\section{Source}

National Cancer Institute. 1p/19q Deletion Analysis Testing Method. NCI Thesaurus.

Code C158848.

A request to enter the specific molecular analysis method used to determine the $1 q / 19 q$ deletion status. 